América sin Nombre, n.o 23 (2018): 243-254

DOI 10.14198/AMESN.2018.23.20

ISSN: 1577.3442 / eISSN: 1989-9831

Fecha de recepción: 10/04/2018

Fecha de aceptación: 23/05/2018
Modo de citación de este artículo:

Rodriguez-Mansilla, Fernando. "Luchadores patéticos: perspectivismo en "Fénix" de J. R. Ribeyro y "Jacob y el otro" de J. C. Onetti”. Madurez de la joven poesía mexicana. Alejandro Higashi e Ignacio Ballester (coordinadores). América sin Nombre, 23 (2018): 243-254, DOI: 10.14198/ AMESN.2018.23.20

Link para este artículo: http://dx.doi.org/10.14198/AMESN.2018.23.20

\title{
Luchadores patéticos: perspectivismo en «Fénix» de J. R. Ribeyro y «Jacob y el otro» de J. C. Onetti
}

\author{
Pathetic wrestlers: perspectivism in «Fénix» by J. R. Ribeyro and «Jacob and the other» \\ by J. C. Onetti
}

\author{
Fernando Rodriguez-Mansilla* \\ Hobart and William Smith Colleges (EE.UU)
}

\section{Resumen}

Este trabajo presenta un análisis comparativo de «Fénix» de Julio Ramón Ribeyro y «Jacob y el otro» de Juan Carlos Onetti. Ambos autores tienen proyectos literarios que convergen en su visión del mundo, el perfil de sus personajes y ciertos recursos narrativos. Los protagonistas de estos cuentos son luchadores patéticos, porque han tenido carreras fracasadas, nadie les tiene ya fe y su victoria tampoco será reconocida. El análisis se enfoca en el recurso del perspectivismo, o multiplicidad de voces narrativas, y su función en ambos cuentos. Finalmente, se presta atención a la presencia del escepticismo en el desenlace de estos relatos. Mientras para Ribeyro la lucha, aunque no conduzca a nada, otorga dignidad al hombre, para Onetti, luchar, aunque se sepa que se va a perder, es lo que otorga emoción y sentido a la existencia.

Palabras clave: Ribeyro, Onetti, «Jacob y el otro», «Fénix», cuento.

\begin{abstract}
This article offers a comparative analysis of «Fénix» by Julio Ramón Ribeyro and «Jacob y el otro» by Juan Carlos Onetti. Both authors have literary projects that merge in terms of worldview, profiles of their characters, and certain narrative devices. The protagonists of these two short stories are pathetic fighters, in the sense that they both failed in their athletic careers, nobody keeps the faith on them, and their victory won't be praised. The analysis focuses on narrative perspectivism (the variety of narrative voices) and its function in each short story. Finally, I pay attention to the presence of skepticism in the ending of the both narratives. While in «Fénix» fight seems unproductive but provides human dignity, in "Jacob y el otro», fight, although everybody always fails, represents the liveliest emotion for human beings.
\end{abstract}

Keywords: Ribeyro, Onetti, «Jacob y el otro», «Fénix», story.

* Es doctor en literatura hispánica por la Universidad de Navarra y profesor titular en Hobart and William Smith Colleges, Nueva York (Estados Unidos). En torno a literatura hispanomericana contemporánea, ha publicado Guía de lectura de Los cachorros en la editorial Cénlit, así como un puñado de artículos sobre Mario Vargas Llosa, Julio Ramón Ribeyro y Juan Carlos Onetti. 
Este trabajo parte de una intuición: la de que los universos de Julio Ramón Ribeyro (1929-1994) y Juan Carlos Onetti (1909-1993) son afines. Por ende, un estudio comparativo puede arrojar nuevas luces sobre sus respectivas obras, a partir de sus perfiles como autores, su manejo de ciertos recursos narrativos y el desarrollo de una temática. Ribeyro y Onetti no pertenecen exactamente a la misma generación, pero sus intereses literarios coinciden de la mano del proceso de la narrativa urbana que experimentan sus países. Para Onetti, se trata del Río de la Plata entre los ańos 30 y 40, cuando empieza a escribir sus primeros cuentos, recogiendo la experiencia del sujeto de la gran urbe, incomunicado y escéptico (Rama y Mattalía 19-31). Para Ribeyro, se trata del Perú de los años 50, cuando aparece el neorrealismo como estética que busca retratar la ciudad con los problemas sociales y existenciales que la circundan (González Vigil, «La narrativa» 238-243).

Un primer aspecto común entre Ribeyro y Onetti corresponde a rasgos personales. Ambos son escritores solitarios, con una vida literaria discreta y ajena a los reflectores. Javier de Navascués comenta sobre el peruano: «No deja de ser cierto que Ribeyro siempre huyó de la notoriedad pública y que trató de llevar, en la medida de sus posibilidades, una vida alejada del relumbrón y los compromisos adquiridos» («Una tensión»171). Onetti fue un invitado de última hora en el Boom, gracias al apoyo de Mario Vargas Llosa y Gabriel García Márquez, los líderes del movimiento, y para cuando su nombre alcanzó las marquesinas, en los años 70, su obra ya estaba prácticamente concluida: tan solo le quedaba escribir Dejemos hablar al viento y un puñado de cuentos, de los cuales "Presencia» es el más notable. De todos es conocido el poco "profesionalismo" con el que Onetti se dedicaba a la escritura, su falta de disciplina y el desgano que lo llevó, en los últimos años de su vida, a no levantarse de la cama. Por su parte, Ribeyro tuvo una vida tranquila, asimismo lejos de polémicas, en París, desde los años 60 , viviendo de su trabajo en una agencia de prensa y agregado cultural para la Unesco después. Abelardo Oquendo también advirtió su falta de "profesionalismo literario» en el prólogo a Prosas apátridas aumentadas: «Ribeyro parece lo más alejado que pueda encontrarse de un profesional. Es decir, Ribeyro no ejerce la literatura, a la manera de la medicina o la administración de empresas, digamos; vive con ella (no por ni para, ni mucho menos, de ella)» (Oquendo 10). Esta actitud común en ambos ha afectado, evidentemente, a su lugar en el canon literario hispanoamericano: se trata de escritores segundones no por falta de talento, sino por desinterés en ubicarse en primera fila. Como resultado, son reconocidos y admirados por quienes los han leído, mas no famosos.

Parte de sus respectivos perfiles es, además, su distanciamiento de la política, fenómeno llamativo en una época, como la década de 1960, en que las tomas de posición ideológica estaban a primera orden. De Onetti se sabe que, como amigo de Luis Batlle Berres, se le podía identificar como un "colorado» o centroderechista, mas nunca hizo proselitismo como escritor ni se aprovechó de la política para obtener algún rédito literario. Su exilio, como se sabe, fue motivado por un escándalo público, absurdo e injusto a todas luces, sobre todo para quien no era considerado un enemigo (tampoco un amigo) de la dictadura uruguaya (Gilio y Domínguez 169-202). Algo parecido ocurre con Ribeyro: se le puede identificar, por el mensaje que se desprende de sus primeros cuentos, cercano al socialismo y hasta le debió a la dictadura de Juan Velasco Alvarado su puesto de trabajo en la Unesco (que confirmaron los gobiernos democráticos peruanos subsiguientes), mas nunca militó ni defendió una causa política ${ }^{1}$.

Ya entrando a sus respectivas obras, Ribeyro y Onetti sienten predilección por personajes fracasados o que están al borde del fracaso. Probablemente se trata de un rezago de lecturas existencialistas o, inclusive, una reminiscencia romántica que se identifica con el roto o el sobreviviente, en oposición al personaje exitoso que el capitalismo consolidó como el modelo del apacible burgués. Los personajes de Onetti suelen ser individuos opacos, desengañados o mediocres que sueñan, de puro aburridos, sin mover un dedo por hacer realidad sus sueños, oprimidos por una urbe que les quita las energías o derrotados por la molicie de la vida en una ciudad de provincias llamada generalmente Santa María. Los de Ribeyro son, en una caracterización ya clásica, los «mudos» de la sociedad: los marginales, excluidos que por ende no tienen voz; tal es la explicación al título de La palabra del mudo para la recopilación clásica de sus cuentos. En estos, abundan también los mediocres, a veces supuestamente talentosos, que se quedaron estancados en algún momento de su vida;

1. Solo consta una excepción. Ribeyro apoyó públicamente la estatización de la banca llevada a cabo por el gobierno de Alan García (1985-1990), a la que se oponía Mario Vargas Llosa. La causa de este comportamiento de Ribeyro es explicada por el propio Vargas Llosa en El pez en el agua (313-314). 
los desclasados, a los que les cuesta aceptar que han caído en la escala social; o los despreciados, por ser pobres o simplemente por su físico o actitudes desfasadas. Los personajes de Onetti no se quedan atrás en su marginalidad, pues «se descubre una significativa proporción de inmigrantes, extranjeros, prostitutas y desclasados" (Aínsa 68) y en esa medida también forman parte de los excluidos de la sociedad.

Enlazados por su predilección hacia el fracaso como tema literario, el estudio de las obras de Ribeyro y Onetti puede confluir alrededor de sus respectivos cuentos «Fénix» (1962) y "Jacob y el otro» (1961). En estos relatos, la acción principal es la lucha cuerpo a cuerpo. Los protagonistas se hallan ante un desafío en el que deben enfrentar a rivales que son de antemano favoritos, pues tanto Fénix como Jacob son aparentemente débiles, por viejos, fuera de forma o de plano por haberse dejado vencer, hace ya tiempo, por la mediocridad de su rutina. Ambos son luchadores patéticos: representan la contracara del luchador todo músculo, virilidad y triunfo. La lucha libre, en los relatos de Ribeyro y Onetti, está plasmada como una farsa en un entorno miserable, el de remotos pueblos en los que los protagonistas han ido a parar como resultado de su fracaso. En el caso de «Fénix», encontramos un luchador al que, tras ser una promesa en el boxeo de la capital, noquearon muchas veces y acabó en un circo pobre, comido por los mosquitos. Jacob, en cambio, según cuenta su manager Orsini, es un ex campeón mundial que tan solo necesita recuperarse un poco, cuando por lo que se ve se trata de un viejo luchador a todas luces caído en desgracia, derrotado y sin opción de competir profesionalmente que va dando tumbos por Bolivia y el norte de Argentina.

¿Qué tiene de especial la lucha libre como tema literario? Probablemente su interés guarda semejanza con el que posee el boxeo, aunque se trate de prácticas distintas. En «Recordando a Julio Ramón Ribeyro», una entrevista de 1986 (publicada recién en 1995) a Ribeyro y Alfredo Bryce Echenique, el primero revelaba su interés por el boxeo como tema literario contando que tenía un guion cinematográfico inédito: «Era la historia clásica: un obrero de Chiclín que entra a boxear, se vuelve un gran campeón y termina como catchascanista [sic] y de mendigo, al final» (46). Bryce comenta lo dicho por Ribeyro poniendo de manifiesto el trasfondo de la lucha libre (o "cachascán», como se denomina en países andinos) para el escritor: «El catchascán [sic] es la prostitución de un boxeador, así como la fumigación es la prostitución de un aviador» (46). Efectivamente, la lucha libre es la degradación del boxeador, a lo que se arrastra para sobrevivir cuando no puede competir en serio. La lucha libre, entonces, puede entenderse como la metáfora de la vida del fracasado, el último rincón, el más miserable, en el que puede habitar ${ }^{2}$. Los personajes de Fénix y Jacob también son patéticos porque son fingidores, pretenden lo que no son. Esa distancia entre lo aparente y lo real es lo que se explora a través de las miradas múltiples, las de personajes con función narrativa, fenómeno que en este trabajo denominamos llanamente perspectivismo.

\section{Perspectivas tramposas en la narrativa}

Observemos, primero, las perspectivas narrativas en "Jacob y el otro». Fernando Aínsa revela el mecanismo del cuento: «Los más sólidos efectos del relato están estructurados a partir de las diferentes versiones de una misma historia en la que se van eludiendo los datos básicos, apenas revelados en las últimas líneas» (143). Además del hecho de que contamos con tres versiones (la del médico Díaz Grey, el narrador y el príncipe Orsini) de los acontecimientos, hay un detalle adicional en el que puede identificarse uno de los rasgos esenciales de la narrativa onettiana: estas tres miradas están dispuestas de forma tal que el orden estrictamente cronológico de los hechos narrados se ha alterado para que el lector mezcle tiempos, siga pistas falsas que generen suspenso y acabe por caer en la trampa de la narración de «Jacob y el otro». En la siguiente Figura 1 se identifican las tres partes del cuento de acuerdo con quién tiene a su cargo la narración, el tiempo al que se refieren los hechos narrados y un resumen de lo que se cuenta. Los capítulos van entre paréntesis ${ }^{3}$.

2. Aún en tiempos recientes, los escritores apelan a la lucha cuerpo a cuerpo para expresar algún tipo de reflexión de índole vital. Roberto Bolaño apelaba a la imagen del luchador de sumo para plasmar su propia lucha contra la enfermedad (Cercas 152). En sus años de Princeton, Ricardo Piglia empezó a entrenar en un gimnasio y le sorprendía el interés de los boxeadores para que sus historias fueran recogidas, conocedores de su valor como tema literario (268-269). Una buena antología, en inglés, sobre el boxeo en la literatura es la de William Cox.

3. Este tipo de análisis, fundamental para entender la naturaleza de la narrativa onettiana y su carácter formador de significados, también se practica en el inspirador estudio, ya clásico, de J. Ludmer sobre Para una tumba sin nombre (151-156). También se aplica en el de Rodríguez Mansilla ( Un narrador cínico») dedicado al cuento «Esbjerg, en la costa». 


\begin{tabular}{|c|c|c|}
\hline $\begin{array}{l}\text { Cuenta el médico (I): } \\
\text { Presente y pasado inmediato (entre sábado } \\
\text { por la noche y madrugada del domingo) }\end{array}$ & $\begin{array}{l}\text { Cuenta el narrador (II-V): } \\
\text { Pasado cercano } \\
\text { (toda la semana previa, desde el domingo } \\
\text { anterior hasta el viernes por la noche) }\end{array}$ & $\begin{array}{l}\text { Cuenta el príncipe (VI): } \\
\text { Pasado reciente } \\
\text { (sábado desde la mańana hasta la noche) }\end{array}$ \\
\hline $\begin{array}{l}\text { Un hombre llega gravemente herido } \\
\text { al hospital. Díaz Grey lo opera y logra } \\
\text { salvarlo. Al salir del hospital, muy temprano } \\
\text { en la mañana, el médico recuerda que } \\
\text { todo empezó el domingo pasado, cuando } \\
\text { aparecieron un luchador y su manager. } \\
\text { Entonces Díaz Grey había visto al luchador } \\
\text { «moribundo» rezando. }\end{array}$ & $\begin{array}{l}\text { Orsini y Jacob Van Oppen llegan a Santa } \\
\text { María para plantear un desafío y recolectar } \\
\text { dinero con el espectáculo. Se presenta el } \\
\text { Turco Mario, impulsado por su novia } \\
\text { Adriana. Orsini intenta convencerlo de que } \\
\text { no se presente o que se deje vencer (porque } \\
\text { ni siquiera tiene el depósito para el desafío), } \\
\text { infructuosamente. El viernes por la noche, } \\
\text { víspera de la pelea, le propone a Van Oppen } \\
\text { escapar, pero este lo noquea para evitarlo. }\end{array}$ & $\begin{array}{l}\text { Van Oppen le muestra a Orsini que tiene } \\
\text { dinero para sostener el desafío. Orsini está } \\
\text { convencido de que perderá ante el joven } \\
\text { rival. Van Oppen, contra el pronóstico de } \\
\text { Orsini (quien se refiere a él como «difunto») } \\
\text { y contra lo que Díaz Grey también nos dio } \\
\text { a entender al inicio, sube al ring y, con una } \\
\text { táctica prohibida por el reglamento, derrota } \\
\text { al Turco lanzándolo hacia las butacas. }\end{array}$ \\
\hline
\end{tabular}

Figura 1

Si reconstruyéramos el relato en estricto orden cronológico, la disposición de los capítulos sería: II-V, VI y I. La forma en que Onetti dispone los hechos en el relato no es arbitraria, sino que obedece a confundir al lector (o engańarlo más bien) para que se incline a pensar que, como en todo cuento derrotista típico de nuestro autor, Jacob será el que ha sobrevivido tras la operación de Díaz Grey, quien lo ha salvado sin demasiado entusiasmo. Los tres narradores de «Jacob y el otro» (el médico, el narrador y el príncipe) escamotean información, dan por sobreentendidos datos que nos impulsan a leer reconstruyendo la historia dejándonos llevar por expectativas convencionales. El médico nos induce a creer en la muerte de Jacob cuando lo describe como «moribundo» (260), por lo estropeado que estaba, cuando lo vio el domingo anterior a la pelea. En los capítulos a cargo del narrador, este nos revela la farsa que monta Orsini para ganarse la vida junto a Jacob. El gigante se presenta como melancólico, ya que se dedica a beber y luego a llorar por la ruina que es su vida, lamentando no tener la oportunidad de volver a competir en serio. Así, no nos resultaría difícil intuir que ese es el luchador que va a perder. La relación entre Orsini y Jacob se nos presenta como paterno-filial, ya que el príncipe lo protege y lo guía como manager, con una dedicación que nos haría dudar de que lo explota (cosa que probablemente hace, solo que con una gran suavidad). Orsini se ve a sí mismo como nińera de Jacob (281) y si lo abandonara lo imagina como un "elefante sin dueño» (282). Jacob es representado como una bestia, un gigante de deseos básicos, cuya alma Orsini alimenta con la poderosa idea de que es eternamente campeón. El rival que enfrentará, el Turco Mario, también tiene algo de animal: es un gigante al que guía y protege Adriana, su novia diminuta, quien lo induce a desafiar a Jacob con la esperanza de ganar el dinero para poder casarse. Se constituyen claramente las parejas Orsini-Jacob y Adriana-Mario. Ambas parejas funcionan igual, como lo ha explorado Javier de Navascués ("Jacob» 21): existe un guía o mediador, astuto y persuasivo (Orsini y Adriana) que propone un modelo a un sujeto dócil con ellos, enorme y velludo (Jacob y Mario). No obstante, pese a insuflar en Jacob el sueño de ser el eterno campeón, el conflicto para Orsini, en realidad, es económico (no tiene siquiera dinero para el depósito del desafío, que teme perder, y tampoco tiene nada que ganar), pero ante Jacob lo plantea como un asunto de honor, el de su «calidad» que puede ponerse en cuestión. En sus pensamientos compasivos frente a Jacob, Orsini identifica el acto de romper la ilusión de ser campeón con un desengaño amoroso (284).

Ahora bien, el privilegio del narrador es que puede contar los pensamientos de Orsini, sus angustias económicas en esos días previos a la pelea y sus argucias para salirse con la suya, así como su desafío privado con Adriana y Mario. Son detalles que nadie más en el pueblo había conocido. Se trata del drama tras bambalinas del espectáculo que ofrecerían el sábado por la noche. Este mismo narrador tiene la misión de mostrarnos la otra cara de Jacob con Orsini. Inesperadamente, el gigante se rebela ante la propuesta de su manager, otrora niñera, y lo engaña para quedarse en Santa María a enfrentar al Turco, confiado en poder vencerlo. Con ello, se nos revela que Jacob no era simplemente la «bestia» sino que pudo ser más astuto que su mentor, quien acaba en el relato sintiéndose medio estúpido, borracho y sin entender lo que ocurre (Navascués, «Jacob» 25).

La parte final del cuento, que en el orden cronológico correspondería, en verdad, a su centro, es el desafío del sábado por la noche. El príncipe abandona 
su rol protector y solo quiere seguir el curso de los acontecimientos. Como Díaz Grey ya nos advirtió del gigante moribundo al que logró salvar y sabemos de la juventud de Mario de la mano de su enérgica novia Adriana, así como los esfuerzos de Orsini para evitar el combate, resulta convincente que el príncipe nos adelante la derrota de Jacob y que adopte, por ende, una actitud cansina al narrar los acontecimientos. Tal como Díaz Grey, el príncipe también nos confunde: imagina la cantada victoria de Mario «con la novia pequeña y dura aullando de triunfo y rabia» (291); se refiere a Jacob como «el difunto» (291) antes de subir al cuadrilátero; $y$, consciente de la pantomima, sostiene que antes de empezar la pelea "tuve tiempo apenas para un par de payasadas» (291). Como advierte la jugada antirreglamentaria, el príncipe considera que Jacob "había ganado o no, según se mirara» (292). Ante la trampa de Jacob y la derrota del Turco, quien era el favorito del público, todos pierden el control. El menos pensado ha ganado y la farsa se ha vuelto triste realidad. El muchacho derrotado, que parecía muerto, no ha fallecido, como podemos entender ahora recordando el primer capítulo del cuento. El final de Mario no llega a ser trágico, no solo porque se salva (aunque nunca se nos dice cuál será su estado final), sino porque su novia no deja de golpearlo enfurecida (inmediatamente después de su derrota y cuando va a verlo al hospital), sintiéndose derrotada ella misma más que el propio Turco.

Este recuento de las acciones del relato, según las plantea su inteligente estructura narrativa, permite observar el engaño como motivo tanto de la generación de las acciones como de los personajes implicados. La narración de "Jacob y el otro" es una trampa para su lector, pues juega con sus expectativas y lo confunde con el desgano de los tres narradores, que lo instan a asumir pistas falsas. Similar operación se encuentra en sus protagonistas: Orsini pretende engañar a toda Santa María para beneficiarse con el espectáculo de Jacob, supuesto campeón mundial; Jacob lo engaña para enfrentar al Mario; Díaz Grey nos engaña sin proponérselo, más bien como resultado de su apatía para ofrecernos datos sueltos que nos llevan a atar cabos incorrectos; finalmente, Adriana y el Turco intentan aprovecharse de la aparente vejez de Jacob y, pese a que son los únicos que intentan jugar limpio, serán derrotados. Cualquier expectativa que se formaba el lector es destruida ${ }^{4}$.

4. Vargas Llosa también detecta esta cadena de trampas y engaños que genera el uso de tres perspectivas: "[Los tres
Este tema, la trampa, es tanto mecanismo narrativo como anécdota caracterizadora de la narrativa onettiana. En el fondo, el autor uruguayo nos cuenta más o menos la misma historia siempre: alguien cree que puede ganar dinero fácil, por un golpe de fortuna o porque sobreestima su habilidad (su fuerza en este caso), y fracasa inevitablemente ${ }^{5}$. Esto se evidencia, sobre todo, en las apuestas a las carreras de caballos, asunto al que Onetti dedicó varios relatos y episodios de novelas (Rodríguez Mansilla, «Por una cabeza» 390-396). En "Jacob y el otro», la apuesta se traslada del hipódromo al cuadrilátero: la misma emoción, el mismo peligro, la misma trampa y la misma decepción.

A continuación, veamos la forma en que se ha construido el relato de "Fénix». Según señala Peter Elmore resaltando el elemento innovador de este relato en la obra de Ribeyro, «la construcción misma de Fénix remite a la arquitectura verbal de Faulkner: en el texto se suceden, polifónicamente, treintaidós monólogos de seis personajes, como en un eco estructural de El sonido y la furia» (112). Estas distintas perspectivas van dándonos impresiones del espectáculo desde dentro (con las voces de quienes trabajan en el circo) como desde fuera (con las voces de los militares asistentes). El contraste de estas voces genera sentimientos encontrados, que van desde la compasión hasta el humor más cruel, pasando por el patetismo que nos transmite el ambiente deplorable del circo y el drama humano de sus trabajadores. Si bien logramos hacernos una idea en torno

narradores] van relatando los deliciosos pormenores -la expectativa de los sanmarianos, las pequeñas anécdotas de la intriga, sus rumores, chismes, y la hechicera personalidad del falso príncipe, que no solo vive de la mentira sino la contagia a todo su entorno-, hasta el cráter final, esa pequeña en la que el borracho y ruinoso viejo en que está convertido el gigante hace volar por los aires, despatarrado, al fornido muchachote local que todos daban por ganador» (El viaje a la ficción 146). Cueto, por su parte, reconoce únicamente la perspectiva de Orsini como origen del engaño que sufre el lector en el desenlace, pues este "es una evidente sorpresa contra todo lo que anunciaba el relato, es decir, la derrota de Jacob a manos de Mario. Esta sorpresa se debe obviamente a que hemos seguido la historia desde el punto de vista del lúcido, escéptico, irónico, atormentado Orsini, un personaje onettiano por excelencia» (65-66).

5. La explicación más plausible a este fenómeno en Onetti es que el personaje siempre fue un fracasado. Es decir, «el fracaso no es el resultado de una vida de esfuerzo y de lucha. Antes que conclusión al final de camino, es un estado natural» (Cueto 14). 
a cada personaje que inserta un monólogo (Fénix, Max, Irma, Chacón, el teniente Sordi y su ordenanza Eusebio), todo lo que dicen y hacen se proyecta hacia el centro del espectáculo de aquella tarde: el enfrentamiento de Chacón, el dueño del circo, con el luchador Fénix, que lleva disfraz de oso ante la enfermedad del verdadero animal.

A partir de la dificultad de llevar adelante el show, conoceremos la explotación y el abuso que casi todos sufren (salvo Chacón) bajo la carpa. Irma es quien muestra la mirada más compasiva hacia Fénix, quizás porque en el pasado tuvo la esperanza de que él la rescatara del circo, aunque ahora está resignada a verlo sometido también al patrón y no deja de identificarlo con un animal, enorme y pasivo, sin juicio para actuar. Max, el enano del circo, se muestra hostil y crítico, siempre a la defensiva, porque ha sufrido mucho en la vida. Fénix, por su parte, es un nostálgico que habla a Max de sus sueños de volver a la costa, lo que significaría encontrar una nueva oportunidad, pero no mueve pieza. Marcial Chacón, en oposición a estos tres personajes, resulta menos simpático al lector, ya que se siente todopoderoso, comete abusos constantes hacia sus empleados y el propio oso, su único móvil es el dinero y por eso mismo desea mantener las apariencias para que el espectáculo se realice. A estos cuatro personajes del circo se unen los espectadores, el teniente Sordi y Eusebio, con sus prejuicios machistas y elementales. Ambos militares, naturalmente, no tienen idea de lo que ocurre tras bambalinas en el circo, creen que la lucha es contra un oso de verdad e incluso si alguno intuye la indefensión de Irma, por ejemplo, no tiene problema en darla por válida. Las observaciones de Sordi, Max y Eusebio son las que dan al relato su tinte más grotesco y cómico. El humor en Fénix es carnavalesco, en la medida en que se basa en la degradación de las figuras, cuya autoridad o cualidades se ven rebajadas a través del lenguaje (Bakhtin 9-10). Dentro del universo narrativo, la polifonía es válvula de escape que responde con efectividad a resistir los dos espacios de opresión en el que participan los personajes: el negocio del circo (donde Chacón ejerce la tiranía con sus empleados) y el ejército (donde Sordi tortura a Eusebio) ${ }^{6}$. Ambos

6. El carnaval y la polifonía en «Fénix» han sido abordados por Rodero. Elmore discrepa de la dimensión carnavalesca del texto, porque no advierte ni inversión cómica ni elementos de cultura popular (113). Por nuestra parte, observamos que el mecanismo del humor sí corresponde a la degradación típica de la risa carnavalesca y la lengua popular, sobre todo espacios, por cierto, no son más que una reproducción en miniatura de una sociedad, la peruana, que se transparenta en las relaciones de los personajes, todas marcadas por el desprecio hacia el que es considerado inferior (por falta de dinero, por su aspecto físico o por su género). Por esa razón, Elmore enfatiza las relaciones de poder en «Fénix» como el eje de la narración: la violación sexual y el maltrato físico son las vías de contacto entre los fuertes y los débiles de la historia (113).

Las múltiples perspectivas nos hacen seguir de cerca el drama y vivir esos dos planos de la realidad: el de los espectadores y el de los actores (porque el circo es un montaje). Elegir un narrador extradiegético solo (tercera persona, con una visión exterior) habría sido monótono, como una historia convencional o fábula edificante. Un narrador solo homodiegético (primera persona, digamos en voz de Fénix) hubiera transmitido un mensaje más bien triunfalista. En «Fénix» la narración transcurre mayormente, salvo ligeras evocaciones, en presente, lo cual mantiene la intriga para el lector. En sus discursos, los personajes suelen mostrarnos, a la vez que comentan, lo que ocurre. Piénsese que una narración a la manera onettiana, por ejemplo, que apelara al recuerdo habría destruido todo el interés en el relato.

Resulta interesante observar que en ese mundo tan jerarquizado que se recrea bajo la carpa de Chacón, no existe deseo mimético en términos de René Girard, como sí ocurría en "Jacob y el otro» (Navascués, "Jacob»). Marcial Chacón abusa de Irma, pero Fénix no piensa en matarlo para rescatarla. Fénix es un animal embrutecido; no es digno de admiración de parte de nadie, ni siquiera de Max, quien le muestra solo simpatía por su pasado de hombre fuerte ${ }^{7}$. El perspectivismo en Ribeyro

de parte de Max y Eusebio, quienes se burlan de los que pueden ejercer roles de autoridad o representan una amenaza: los otros enanos eran «requeteenanos» (249), el teniente Sordi es «el barbudo» (251), Chacón es «panzudo» (256), al oso (que debería generar respeto o miedo) le llegan a gritar «oso marica» (258), etc. Fuera de ese recurso del humor carnavalesco, coincido con la reserva de Elmore frente a la lectura de Rodero. Nótese, en cambio, que en Onetti las voces no hacen más que asegurarnos la inestabilidad de lo que se nos cuenta, ya que no se propone ser polifónico: la voz, lingüísticamente hablando, no cambia, pues el narrador habla como Díaz Grey y este como Orsini, sin mayores matices.

7. Esta observación no pretende descalificar el arte narrativo de Ribeyro frente al de Onetti, sino solo dar cuenta de sus proyectos divergentes. Podría afirmarse que esta diferencia radical obedece a los distintos panoramas narrativos a los 
no conduce a visiones conflictivas sobre los impulsos o acciones de sus protagonistas, como sí ocurre en Onetti, donde se asume que cada personaje posee una versión parcial, cuando no tergiversada, de lo que ocurrió. En Ribeyro, todo el énfasis de las perspectivas se encuentra en aliviar la violencia que subyace a las interacciones de los personajes, lo cual promueve un clima que invita al lector a sentir satisfacción por la victoria de Fénix frente a Chacón, aunque no sea permanente.

\section{Los finales y las apariencias}

Evaluemos ahora los desenlaces de cada cuento, pues su análisis nos permitirá anotar discrepancias en el tratamiento narrativo a la vez que algunos puntos de contacto. Ambas historias acaban en zafarrancho general, cuando todo el espectáculo se viene abajo ante lo inesperado: en «Jacob y el otro" por la derrota del Turco Mario y en «Fénix» por la de Chacón. Nótese que son finales inesperados para todos, tanto los espectadores como los personajes cercanos a los luchadores, excepto para sus mismos protagonistas. Jacob y Fénix saben que pueden ganar y lo hacen, contra las expectativas derrotistas de quienes les rodean ${ }^{8}$.

En particular, el final de «Jacob y el otro» no mueve emotivamente al lector, sino a experimentar la extrañeza frente a los hechos narrados, por su

que pertenecen. En Ribeyro la representación de un mundo social tan jerarquizado (de explotadores y explotados, victimarios y víctimas, discriminadores y discriminados), por causas generalmente raciales, obedece a la agenda neorrealista de su tiempo, aunque dicha mirada crítica puede rastrearse en la narrativa peruana al menos hasta el siglo xIx con Clorinda Matto de Turner y otros autores del primer indigenismo. En el caso de Onetti, se debe tomar en cuenta que representa una sociedad más dinámica y moderna (en contraste con la que recrea Ribeyro), y sin una diversidad étnica causante de esa clase de fricciones. Vargas Llosa lo detecta bien cuando contrasta el universo narrativo de Onetti con el de W. Faulkner: «Santa María es una sociedad homogénea de blancos, conformada casi íntegramente por descendientes de origen europeo -alemán, italiano, francés y español a juzgar por los apellidos, sobre todo- y exenta por eso mismo de ese dramatismo brutal del origen étnico que a veces recorre al condado faulkneriano" (El viaje 92).

8. Aunque, por lo visto, Jacob tampoco sale de su asombro. No por nada, Orsini lo describe agitado tras vencer al Turco: «La fatiga le venía de los nervios y no del cansancio» (292). Tampoco se lo creía, al parecer. carácter brumoso, debido al perspectivismo, que impide tomar partido por un contrincante $\mathrm{u}$ otro. La forma del texto se propone dejar al lector perplejo o desengañado frente a cualquier expectativa concluyente que podía haber asumido. En "Jacob y el otro", no compadecemos al Turco, pese a la gravedad de sus heridas, ni tampoco nos alegramos precisamente por el triunfo del ruinoso Jacob, aunque se haya reivindicado consigo mismo. La atmósfera que desarrolla el relato impide adoptar emociones de esa índole respecto a los personajes. Onetti es un aguafiestas y hemos de considerar inclusive el nombre del luchador como una parodia de lo que significa la victoria. En la Biblia (Génesis 32), Jacob luchó contra un ángel toda la noche, lo venció y esa fue la prueba que le puso Dios para llamarlo en adelante Israel y convertir a su descendencia en el pueblo elegido?. El protagonista de "Jacob y el otro» está bien lejos de ser el elegido o de asegurarse la tierra prometida. La victoria de Jacob en el cuento es inútil. Antes de la pelea, Orsini ya había anticipado cómo podría reinventar al luchador con miras a seguir viviendo de las giras: «Ahora en este momento, dentro de unos minutos, llegaba el final de la historia. De esta, la del Campeón Mundial de Lucha. Pero habría otras, habría también una explicación para El Liberal, Santa María y pueblos vecinos» (290). Lo importante para Orsini era mantener las apariencias, en tanto para Jacob era mantener la ilusión que le había impuesto su manager. Desde la perspectiva del supuesto campeón, ganar cometiendo trampa es lo de menos. Se probó a sí mismo que no era el perdedor de antemano como Orsini y Adriana, los aparentemente inteligentes del relato, creían. Ha vencido para seguir viviendo una vida falsa en la que persevera para sentir que es verdad el sueño de ser el campeón mundial.

Ciertamente tampoco creo que se trate de un cuento que "proyecta una visión simpática y optimista de la vida", como quiere Vargas Llosa ( $E l$ viaje a la ficción 145). En el mundo narrativo de «Jacob y el otro» nadie sabe para quién trabaja y nada es lo que parece, ya todo depende de quién lo cuenta. Mario queda fuera de juego porque nunca lo animó un deseo auténtico y todo era mediatizado por Adriana. Este detalle hace que su derrota no

9. Cueto también identifica el origen bíblico del nombre de Jacob, pero su interpretación sigue un rumbo totalmente diferente al trazado aquí, ya que lo vincula con Orsini como un Esaú (57). Su lectura no deja de ser ingeniosa. 
nos apene, ya que se trata de un sujeto sin convicciones, heredero de un negocio boyante, por lo que su victoria no hubiera tenido gloria alguna (como tampoco la tuvo al fin y al cabo la de Jacob). Adriana, por su parte, era una caprichosa y sobreestimó sus posibilidades. Orsini también fue estafado. Jacob ha ganado frente a Orsini, pero poco más: hizo trampa, no es válido, su vida sigue siendo un engaño, nada efectivamente ha cambiado en su vida. No es más ni menos mediocre o decadente por haber vencido, con trampa, al Turco. Solo fue más tramposo que los demás guardando su carta hasta el final. La trampa subsiste por la forma en que se han contado los hechos: disponiendo la pelea al final, cuando en realidad, cronológicamente hablando, estaba en el medio. De hecho, el final de la historia no es la victoria de Jacob, sino la recuperación, casi milagrosa, del Turco tras la cirugía que le hace el doctor Díaz, que es considerada prácticamente una «resurrección» (259).

Ya que ese es el verdadero final, si nos atenemos al desarrollo cronológico de los hechos en «Jacob y el otro", se comprende mejor el comentario de Díaz Grey que da pie a la serie de recuerdos sobre la estancia de Jacob y Orsini en Santa María:

Nunca podría conocer la verdad de aquella historia; con buena suerte y paciencia tal vez llegara a enterarme de la mitad correspondiente a nosotros, los habitantes de la ciudad. Pero era necesario resignarse, aceptar como inalcanzable el conocimiento de la parte que trajeron consigo los dos forasteros y que se llevarían de manera diversa, incógnita y para siempre (259-260).

Así, nunca sabremos qué es lo que quedará en los anales de la memoria colectiva de Santa María: la victoria de Jacob, la derrota de Mario, la "resurrección" de este último o ninguna de las tres cosas. Tal es el efecto del perspectivismo de Onetti ${ }^{10}$. Piénsese que la muerte del Turco es otra expectativa rota de los sanmarianos y de haber ocurrido cargaría la historia de

10. Tras caracterizarlo, certeramente, como «observador mal informado», Elena M. Martínez sostiene, a propósito de la cita que comentamos, que "Díaz Grey, como mediador informante, hace lo que todos los personajes de Onetti: reiterar la imposibilidad de llegar a saber, de comprender todos los detalles que conforman la historia» (74). En última instancia, el recuerdo está basado en la impresión que el tiempo forja sobre los hechos; el concepto del tiempo, como categoría filosófica y de construcción narrativa, en Onetti proviene de Henri Bergson (Ferro 326-327). un hálito trágico (un niño por nacer que perdió a su padre en una apuesta estúpida). Hay muchas vidas, muchos caminos y posibilidades. Lo que parece real puede no serlo. El príncipe Orsini parece príncipe, dice serlo, pero es un estafador. Jacob pretende ser campeón mundial y no lo es (o quizás sí lo volverá a ser, si es verdad lo que dice el príncipe). Del futuro de Mario nada sabemos, quizás se recupera y su novia lo seguirá manipulando. No importa. Él, siguiendo a su novia, intentaba sacar ventaja de la vejez de su rival, no lo respetaba y pensaba ganar dinero fácilmente. No ocurrió así. Esa incertidumbre, la perplejidad ante la vida es lo que da su aliento a la narrativa onettiana. Se trata de apenas insinuar, desde múltiples perspectivas, aquel «fondo definitivo que no tocaremos nunca» como dice el narrador del cuento «Matías el telegrafista» (Onetti 343), para referirse al inefable sentido de la existencia.

El planteamiento de Ribeyro es bien diferente, ya que el conflicto narrativo se propone de forma binaria, reflejando la dinámica de una sociedad fuertemente jerarquizada: explotadores o explotados, liberados o cautivos, ofensores o víctimas. En «Fénix» los personajes también fingen, pero su fingimiento no conduce a sacar ventaja del rival, sino que se propone simplemente mantener las apariencias para que el sistema de explotación siga operando sin cambios y que los que sufren sigan sufriendo, aunque esperanzados en que el mismo sistema que los oprime les brinde en algún momento una salida, por haber mantenido las apariencias y no haber hecho trampa: Irma persevera en ser contorsionista y ser víctima de abuso sexual con resignación (aunque espera que alguien la salve, cual doncella en apuros); Max sabe a qué atenerse por su estatura y solo pide que no se excedan en los golpes; el teniente Sordi piensa que tiene que aguantar la estancia en la selva si quiere volver a la ciudad más adelante; Eusebio tolera los abusos de Sordi, porque confía en que este le ayude a conseguir un ascenso. En el mundo de Ribeyro, esas pequeñas insubordinaciones como la burla o la queja quedan reservadas para el monólogo interior. Ello permite mermar la jerarquización que los asfixia, gesto imposible en el mundo real. De esa forma, los de abajo canalizan su frustración hacia los de arriba.

En «Jacob y el otro", en cambio, las apariencias sirven para que la gente siga sońando con que eso que siente es real y hasta quizás lo es, porque se instaura el relativismo, basado en la inexactitud de los testimonios e impresiones que se recogen, producto de la memoria, caprichosa y tendenciosa, de lo que viven 
los personajes ${ }^{11}$. Los marginales lo seguirán siendo y no hacen más que estafarse los unos a los otros. El mundo sigue girando y la vida en Santa María sigue siendo cansina. En «Fénix», se prefiere el hic et nunc, para canalizar la frustración y poder seguir viviendo, ya que esa es la lucha diaria del oprimido. Los marginales sueñan con la redención y tal vez podrán tener su oportunidad, aunque no hay garantía de que consigan aprovecharla. Fénix puede sentir que ha renacido tras vencer a Chacón, pero el sistema de opresión no cambia.

Tramposos que sacan ventaja de lo que fingen o estoicos que fingen para mantener el statu quo sin rebelarse, tanto en Onetti como en Ribeyro los luchadores no dejan de ser patéticos. La victoria de Jacob no cuenta porque hizo trampa y, ya que nadie creía en él, tampoco nadie lo celebra. Fénix es igualmente patético porque tampoco nadie creía en él, pero este luchador se aferra a una esperanza nueva, basada en haberse salido de sus casillas y no aceptar mantener las apariencias. Si en Onetti el nombre del protagonista nos remite a una tradición bíblica para subvertirla, el del luchador de Ribeyro se propone como un símbolo de esa ilusión de la victoria frente a la adversidad: la resurrección de Fénix, como el ave mítica de Arabia, nos aseguraría que va a volver a ser un hombre libre, fuerte y con voluntad en esa costa que tanto añoraba. Tal sería aquella «extraña metamorfosis liberadora» (Rodero 150) en medio del calor abrasador de la selva, que lleva a Fénix a mirar el futuro con esperanza de ser hombre de nuevo:

Avanzo, libre, hacia el río, con mi cabeza de oso en la mano, decapitado, feliz. Atrás, solo la tienda iluminada del circo. En el circo, Marcial, Max, Irma, Kong, los soldados meones, todo enterrado, todo olvidado. Avanzo hacia el agua, sereno al fin, a hundirme en

11. Este fenómeno también es advertido por Vargas Llosa como uno de los temas obsesivos de Onetti: «La idea de que la vida es representación, una farsa en que hombres y mujeres interpretan los roles que otros les infligen» (El viaje 149). Tan solo discrepo de la última parte de la frase, pues no siempre se trata de papeles que imponen otros. Para varios personajes onettianos, como el príncipe Orsini o Larsen, la farsa es una manera de vivir y para otros es simplemente una afición o un vicio. Más fina me resulta la afirmación de Martínez en torno a este fenómeno: «Los personajes de Onetti llevan a cabo un proceso de reparación y sustitución de la realidad" (67). Más recientemente, Cueto coincide: "Orsini representa la supervivencia de la farsa, es decir, de la falsa representación» (52). ella, a cruzar la selva, tal vez a construir una ciudad. Merezco todo eso por mi fuerza. No me arrepiento de nada. Soy el vencedor (260).

En efecto, al mencionar que lleva la cabeza del oso en la mano, el personaje hace patente que ha dejado de ser un animal y vuelve a ser un hombre con todas las prerrogativas, por lo que se siente «el vencedor». Como apuntamos más arriba, la forma de la narración puede conducir, en una lectura superficial o inmediata, a identificar este tono triunfal como conclusión del relato, ya que es fácil tomar partido, razonablemente, por Fénix frente a los abusos del patrón. Precisamente, Elmore apunta un «delirio liberador y mesiánico», a la vez que una "afirmación final de esperanza» (113) en el protagonista. Rodero, más cauto, observa "un final incompleto» (157), debido a que la historia se suspende cuando Fénix está huyendo y los soldados lo persiguen.

Las palabras de Fénix son conmovedoras, pero se le augura, con seguridad, la muerte. El cuento formó parte, junto con "Al pie del acantilado» $\mathrm{y}$ «El chaco», de Tres historias sublevantes, volumen publicado por Ribeyro en 1964. Si leemos "Fénix» en ese marco, resulta coherente que el personaje muera. "Al pie del acantilado» termina con una escena que promete que todo volverá a empezar (los invasores que acaban de ser desalojados vuelven a invadir otro lugar, por lo que probablemente les acabará ocurriendo lo mismo); «El chaco» se cierra con la muerte del indígena explotado, al que persiguen y matan sin piedad. En «Fénix», pese a los delirios del protagonista, este morirá. Si nos queda duda alguna, el mismo Ribeyro lo declaró en una entrevista publicada 1987, cuando resume así el argumento de "Fénix» en el contexto de Tres historias sublevantes:

Me propuse escribir tres cuentos que describieran tres combates, tres combates perdidos, pues los protagonistas o los personajes principales terminan derrotados. Tienen, eso sí, el mérito de haber combatido. [...] En el tercero, un empleado de circo, que se subleva contra el dueño del circo que lo tiraniza: muere también asesinado. En los tres combates hay una decisión de no claudicar, de luchar hasta el fin (Ampuero 147-148).

De hecho, los dos últimos párrafos de «Fénix» nos brindan suficiente información para intuir ese final aciago que acaba de explicar Ribeyro para el protagonista. En el penúltimo, que desarrolla el monólogo del teniente Sordi, este se propone perseguir a quien considera aún que es un animal: "Doce cholos me 
han dado y antorchas además y un perro. [...] Mi fusil está bien aceitado y en la cacerina tengo mis balas dum-dum. Hay que poner orden aquí, para eso nos pagan y para eso he pasado dos años en Corral Quemado sin quemar un cartucho» $(259)^{12}$. Precisamente a la proximidad de los soldados se refiere Fénix cuando, ya en el último párrafo del texto, apenas después de decirse a sí mismo que es un vencedor, afirma: «Si esas luces de atrás son antorchas, si esos ruidos que cruzan el aire son ladridos, tanto peor. Los llevo hacia la violencia, es decir, hacia su propio exterminio» (260). Debemos suponer a Fénix tan envalentonado que decide enfrentar, según lo indica, al teniente y sus hombres con un resultado que no cuesta imaginar. Ellos están armados, llevan luces y perros, él solo depende de sí mismo. De hecho, el que lo persigan como si fuera un animal nos debe llevar a pensar que su acto de liberación, aquel quitarse la piel del oso, no ha tenido consecuencias reales. Su sensación de haber vencido es efímera y su muerte lo confirmará.

\section{Conclusión}

Para concluir, veamos en qué radica el escepticismo de Ribeyro y Onetti que queda plasmado en sus respectivos cuentos. «Fénix» y «Jacob y el otro» ofrecen dos planteamientos divergentes frente a la lucha entendida como espectáculo. Para Onetti, es un espacio para la reivindicación personal mediante la trampa y el consecuente sentido de fraude que adquiere para todos los involucrados. Para Ribeyro, aunque la lucha se plantea inicialmente como un fraude, acaba siendo verdad: la victoria de Fénix supone una reivindicación, aunque sea efímera, del oprimido; por lo

12. Otro que estaría dispuesto a matar a Fénix sin dudarlo sería el soldado Eusebio, quien extraña disparar. En uno de sus monólogos, declara haber disparado una sola vez, a un zambo (mezcla de negro con indio), «¿Por qué? Ni sé quién sería pero una vez un zambo me rompió la jeta en el Rímac» (251). Entre sus recuerdos, Fénix cuenta que se refieren a él como "zambo" y sus hermanos eran igualmente «zambos» (248). Luchting ofrece un análisis muy detallado del personaje afrodescendiente en Ribeyro (319-333). Por otro lado, nótese el tono paródico en las palabras de Sordi al decir "he pasado dos años [...] sin quemar un cartucho», que remeda la famosa frase del héroe peruano Francisco Bolognesi, quien prometía luchar «hasta quemar el último cartucho». Evidentemente, Sordi no parará hasta matar a Fénix. que, como metáfora, la lucha alcanza un valor moral ausente en Onetti. Encontramos aquí la ética que subyace a todos los empeńos narrativos de Ribeyro, como ha sostenido Navascués («Una tensión»). En el caso de "Fénix», el fracasado puede vencer, al menos en un espacio reducido y miserable que no implica una redención definitiva o futura, ya que sabemos que morirá inevitablemente. Lo importante es luchar, pareciera decirnos Ribeyro. El escepticismo se encuentra plasmado en su recreación de la sociedad jerarquizada, en la que la explotación sistemática no se ve alterada o cuestionada ${ }^{13}$. Fénix sueńa en un entorno tan degradado que no cabe creerle, aunque no dejemos de conmovernos con su historia. Es un perdedor y no se escapará de ese destino.

En Onetti, el escepticismo se plasma en una visión relativista de la victoria y la derrota entre sujetos que, en sus intereses, sus defectos y sueños, no son muy diferentes: todos se mueven por el dinero como meta que puede ayudarles a salir adelante y cambiar su vida, aunque eso nunca ocurra. En el mundo de Onetti el que apuesta pierde, siempre, pero encuentra en la apuesta, en el arriesgar, el sentido de emoción que necesita para sentirse vivo. En Ribeyro, esa emoción vital se encuentra en la lucha a la manera de Sísifo, en la pelea contra una adversidad persistente; a saber, tan solo en los relatos de Tres historias sublevantes: la búsqueda de un hogar en "Al pie del acantilado»; la persistencia de Sixto en resistir, hasta los límites de su humanidad, al abuso del patrón en «El chaco»; la victoria del luchador ruinoso en "Fénix»" ${ }^{14}$. Por último, como decía Ribeyro a Fernando Ampuero en su síntesis del libro, estos

13. González Vigil afirma que el realismo de Ribeyro mezclado con su escepticismo generó, precisamente, «un realismo desencantado, de 'ilusiones perdidas' (Balzac), donde los ideales y las convicciones, igualmente los deseos (incluyendo los turbios) y las maquinaciones (dictadas por un afán de comportarse sin escrúpulos morales, como los demás) naufragan, casi sin excepciones (el mayor contraste es la rebelión y la lucha presentadas en Tres historias sublevantes, 1964)» («En clave fantástica» 107).

14. Ribeyro sintetizaba los temas de Tres historias sublevantes de forma parecida en una entrevista hecha por R. González Vigil: «Tres tipos de lucha: el de la Costa, la lucha del hombre por la vivienda; el de la Sierra, la lucha por la tierra; y el de la Selva, por la dignidad» («Ribeyro: la palabra del autor» 92). En su reconocimiento de «la lucha por la tierra» como tema del cuento «El chaco» percibo un rezago de la agenda indigenista. 
personajes tienen el mérito de haber combatido, sin importar el resultado ${ }^{15}$.

Un botón más, ya para finalizar, del escepticismo común a ambos autores es su tratamiento del valor de la resurrección. La resurrección, pese a su carácter extraordinario, es un acontecimiento, como tantos otros, que se escamotea en "Jacob y el otro", pues se desvía para no impregnar al vencedor (Jacob) de algún tipo de glorificación. El que resucita es el Turco y el único triunfo real (sin trampas) de todo el relato es del doctor Díaz Grey en la sala de operaciones, aunque está tan aburrido con su existencia que ni siquiera le apetece celebrarlo. La resurrección en Ribeyro es efímera o meramente alegórica como propone Elmore (113) y en ese sentido igualmente inútil, porque se escamotea la verdad fatal. Ambos autores, por caminos distintos, se proponen lo mismo: ilusionar a su lector, confundirlo y desengañarlo. El sentido de ese desengaño, no obstante, es diferente en cada uno de ellos. Para Onetti, la emoción de lo que se arriesgó bien vale el fracaso; para Ribeyro, la lucha del débil ante el fuerte es lo que le otorga dignidad a la vida.

\section{Bibliografía}

AínSA, Fernando. Las trampas de Onetti. Montevideo: Alfar, 1970.

Ampuero, Fernando. «El enigma de la transparencia: Julio Ramón Ribeyro». Gato encerrado. Crónicas/ entrevistas/ reportajes. Lima: Peisa, 1987, 141-152.

BaKhtin, Mikhail. Rabelais and His World. Bloomington: Indiana University Press, 1984.

Cercas, Javier. Soldados de Salamina. Barcelona: Tusquets, 2001.

Cox, William. Boxing in Art and Literature. New York: Reynal \& Hitchcock, 1935.

15. Esta postura de Ribeyro encuentra su reflejo en el interés en la alquimia que lo llevó a plasmar el enigma del jardín en su cuento «Silvio en el rosedal». Así se lo comentaba en entrevista a W. Luchting: «La idea de que lo importante en la vida es el esfuerzo desplegado y no la meta a la cual se llega. Desde hace algún tiempo me intereso en la alquimia, pero no por la alquimia operativa (es decir, la piedra filosofal, la conversión en oro), sino por la parte teórica. [...] Los que buscaban la piedra filosofal ocupaban toda su vida en la empresa, aunque muchas veces estaban convencidos de que no la iban a encontrar; el propio camino se convertía en el fin» (ctd. en Luchting 155). Ribeyro publicó un ensayo sobre su fascinación alquímica llamado «La alquimia, hoy».
Cueto, Alonso. Juan Carlos Onetti. El soñador en la penumbra. México: Fondo de Cultura Económica, 2009.

Elmore, Peter. El perfil de la palabra. La obra de Julio Ramón Ribeyro. Lima-México: Pontificia Universidad Católica del Perú- Fondo de Cultura Económica, 1993.

Ferro, Roberto. Onettil La fundación imaginada. La parodia del autor en la saga de Santa María. Córdoba: Alción Editora, 2003.

Gilio, María Esther y Carlos M. Domínguez. Construcción de la noche. La vida de Juan Carlos Onetti. Buenos Aires: Planeta, 1993.

GonZÁLez VIGIL, Ricardo. «La narrativa peruana después de 1950». Lexis 8.2(1984): 227-248.

González VigiL, Ricardo. «Ribeyro: la palabra del autor» $\mathrm{y}$ «En clave fantástica». Años decisivos de la narrativa peruana. Lima: Editorial San Marcos, 2008, 91-97 y 105-107.

Luchting, Wolfgang. Estudiando a Julio Ramón Ribeyro. Frankfurt: Vervuert, 1988.

Ludmer, Josefina. Onetti. Los procesos de construcción del relato. Buenos Aires: Sudamericana, 1977.

Martínez, Elena M. Onetti: estrategias textuales y operaciones del lector. Madrid: Verbum, 1992.

Mattalía, Sonia. La figura en el tapiz (teoría y práctica narrativa en Juan Carlos Onetti). Londres: Támesis, 1990.

Navascués, Javier de. «Julio Ramón Ribeyro: una tensión resuelta entre el silencio y la escritura». América sin Nombre 13-14(2009): 170-175.

NAvAscuÉs, Javier de. «Jacob y el otro: una lectura desde el deseo mimético». Letral 2(2009): 21-29.

Onetti, Juan Carlos. Cuentos completos. Madrid: Alfaguara, 1994.

Oquendo, Abelardo. "Alrededor de Ribeyro». Prosas apátridas aumentadas. Lima: Editorial Milla Batres, 1978, 9-20.

Piglia, Ricardo. Los diarios de Emilio Renzi, III. Un día en la vida. Barcelona: Anagrama, 2017.

Rama, Ángel. "Origen de un novelista y de una generación literaria». En El pozo. Juan Carlos Onetti. Montevideo: Arca, 1969, 49-101.

«Recordando a Julio Ramón Ribeyro». Debate I6.80(I995): 46-48.

Ribeyro, Julio Ramón. «La alquimia, hoy». Cielo abierto 3.7(1980): 20-26.

Ribeyro, Julio Ramón. Cuentos completos. Madrid: Alfaguara, 1994.

Rodero, Jesús. «Fénix: del carnaval y el juego con el mito». Asedios a Julio Ramón Ribeyro. Ed. Ismael Márquez y César Ferreira. Lima: Fondo Editorial de la Pontificia Universidad Católica del Perú, 1996, 149-159. 
Rodríguez Mansilla, Fernando. «Un narrador cínico y el amor: Esbjerg, en la costa de Juan Carlos Onetti». Itinerarios 7(2008): 165-174.

Rodríguez Mansilla, Fernando. «Por una cabeza: los caballos en la narrativa de Juan Carlos Onetti». Revista de critica literaria latinoamericana 79(2014): 385-397.
VArgas Llosa, Mario. El pez en el agua. Barcelona: Seix Barral, 1993.

Vargas Llosa, Mario. El viaje a la ficción. El mundo de Juan Carlos Onetti. Barcelona: DeBolsillo, 2015. 